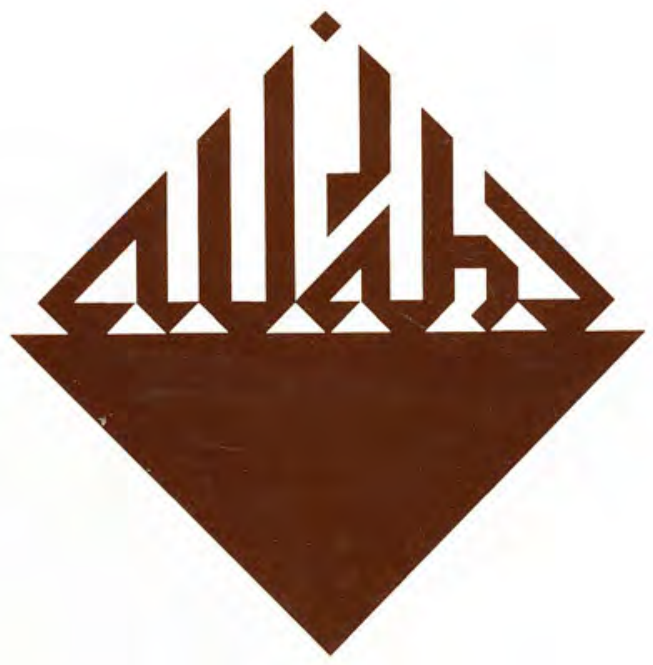

The ORIGIN OF THE ISLAMIC ReFORM MOVEment in MinangKabAU: LIFEAND THOUght OF ABDUL KaRIM AMRULLAH Murni Djamal

NOTES TOWARDS THEHISTORY OF QUR'ÂNIC EXEGESIS INSOUTHEAST ASIA R. Michael Feener 


\section{SIIIDAISLAMIIIKA \\ Indonesian Joumal for Islamic Studies \\ Vol. $v$, no. 3, 1998}

EDITORIAL BOARD:

Harun Nasution

Mastuhu

M. Quraish Shihab

A. Aziz Dahlan

M. Satria Effendi

Nabilah Lubis

M. Yunan Yusuf

Komartuddin Hidayat

M. Din Syamsuddin

Muslim Nasution

Wahib $\mathrm{Mu}$ 'thi

EDITOR-IN-CHIEF:

Azyumardi Azra

EDITORS:

Saiful Mujani

Hendro Praseiyo

Iolian H. Meuleman

Didin Syafruddin

Ali Munhanif

Assistants to THE EDITOR:

Arief Sublan

Oman Fathurrahman

Heni Nuroni

ENGLISH LANGUAGE AdVISOR:

Donald Potter

Arabic Language Advisor:

Nursamad

Cover Designer:

S. Prinka

STUDIA ISLAMIKA (ISSN 0215-0492) is a journal published quarterly by the Institut Agama Islam Negeri (IAIN, the State Institute for Islamic Studies) Syarif Hidayatullah, Jakarta. (STT DEPPEN No. 129/SK/DITJEN/PPG/STT/1976) and sponsored by the Department of Religious Affairs of the Republic of Indonesia. It specializes in Indonesian Islamic studies, and is intended to communicate original researches and current issues on the subject. This journal warmly welcomes contributions from scholars of related disciplines,

All articles published do not necessarily represent the views of the journal, or other institutions to which it is affiliated. They are solely the views of the authors. The articles contained in this journal liave been refereed by the Board of Editors. 


\title{
Kebangkitan Islam dan Negara: Beberapa Kasus dari Asia Tenggara
}

\author{
Robert W. Hefner dan Patricia Horvatich (eds.), Islam in an Era of Nation \\ States: Politics and Religious Renewal in Muslim Southeast Asia (Honolulu: \\ University of Hawaii Press, 1997), 327 halaman.
}

\begin{abstract}
Since the 1970s, Muslims in Southeast Asia have been experiencing a religious revival which is unprecedented in their social bistory. This revival may be a product of several important factors, yet there are three leading trends that this book found to be particularly compelling: 1) the success of civic education at the grassroots level, 2) the emergence of a Muslim middle class, and 3) the rise of a new regional Islamic discourse which is more oriented toward the basic demands of the general public, and not merely directed toward those within religious circles.

These factors cannot be totally excluded from the political experience of Muslims in the post-colonial era, especially from their experience with newly constructed nation-states. The infrastructural reach of this political construct goes far beyond the concept of the state known in traditional polities. Nation states exert great influence on many aspects of public life, yet also intrude into the most intimate domains of private lives of Muslims. This modern institution has thus frequently been characterized as a threat to forms of traditional organization and authority. Yet, on the other band, the nation state is recognized as a new opportunity for many Muslims to realize a common dream: widespread social and religious transformation toward a more Islamic society. In short, the idea of a nationstate has in certain instances encouraged the Muslim socio-political imagination, and has intensified the debate over ideal constructions of Muslim society.

The majority of the contributors to this book have taken an anthropo-
\end{abstract}


logical approach, and have presented detailed descriptions and analyses of Muslim encounters with nation-state. They strongly emphasize the experience of Muslims in three Southeast Asian states: Indonesia, Malaysia, and the Philippine. The discussions are divided into three general categories. The first deals with relations between the state and Islamic political organizations in Kotabato, Philippines (by Thomas M. Mckenna), and in In. donesia (by Robert W. Hefner concerning ICMI and Andrée Feillard concerning NU). The second part discusses various Islamic reform movements in rural societies, such as Islamic modernism in Gayo, Indonesia (by Jobn R. Bowen), the Abmadiyyah movement Simunul Island, Philippines (by Patricia Horvatich), and the dakwah movements in Malaysia (by Shamsul A.B). The third part analyzes modes of Muslim responses at the grassroots level towards various reform movements and discourses in Negeri Sembilan, Malaysia (by Michael G. Peletz), and South Sulawesi, Indonesia (by Martin Rossler).

This book is of significant importance for several reasons. First, regarding methodology, its contributors have demonstrated an awareness of the danger of orientalists essentialism which, in the past, has tended to emphasize "the great tradition", as well as anthropologists ethnographism which has been exclusively concerned with "the little tradition". The ar. ticles of this book succeed in transcending these scholarly traditions in order to accurately describe the creative tension which exists in religious experiences of Muslims in Southeast Asia, between the imperatives of religion and history, between regional Muslim culture and local identities.

Another important merit is the contributor effort to distinguish political Islam from specific historical backgrounds to which it is frequently ascribed, namely, the common preoccupation with the Middle-Eastern el. ements rather than Islam itself. Therefore, the book provides an opportunity to reevaluate the diversity of Islamic politics in the modern world, and argues that political Islam is neither monolitics nor identical with. political struggles being waged in Middle East.

Finally, the area focus of this book, Southeast Asia, provide recognition that this region is of critical important in the Islamic world. Since the worlds' largest population reside in Indonesia, and since there are actually more Muslims living in Southeast Asia than the whole of the Middle East, its significance in global Muslim culture is crucial, By bighlighting many promising developments in the social, economic, and political spheres of Southeast Asian Muslims, the contributors to this effort have underscored the value of Islam in the region, and have provided a better understanding of Muslion responses to modernity. 
مر اجعنة كتاب

\section{النهضفة الاسلالامية والدولة: \\ قضايا في جنوب شرقي آسيا}

Robert W. Hefner \& Patricia Horvatich (ed.s), Islam in an Era of Nation States:

Polifies and Religious Renewal in Muslim Southeast Asia (Honolulu: University of ( Hawaii Press, 1997)

خلاحة: إنه منذ عقد العشرينيات مـن القـرن شهـدت الامـة الاسـلامية جنسوب

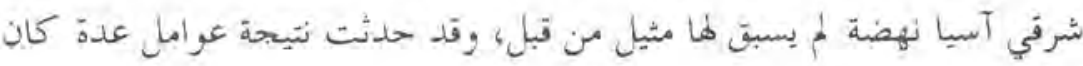

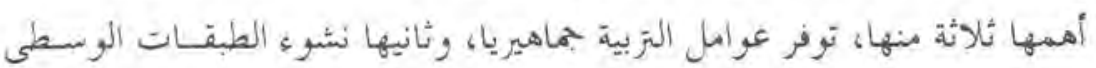

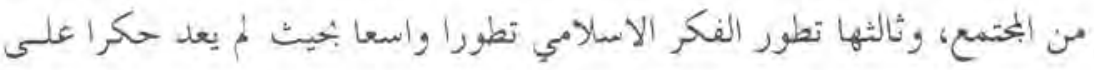
طائفة ميعينة من رجال الدين، ورم تقتصر بحالاته على حلدود معينـة إنما اتجهـه إلى حاجة البحتفع بصفة عامة. ولا بمكي فصل هذه العوامل بل ترتبط أشد الارتباط بما كان يعاني منسه

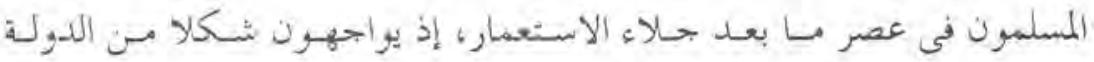

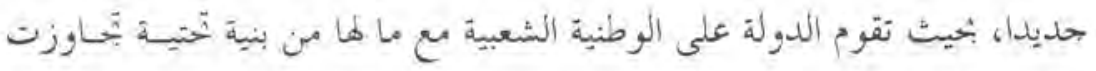
مفاهيم الدولة التقليدية، فقد أصبحث نفوذ الدولة (الحديثة) تتوستسع في ثوجيـه

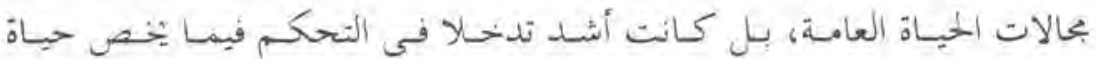


المسملمين ، وهكذا باءت هذه الهيئة من ناحية تئكل خعطررا يتهـدد بقـاء الميئات

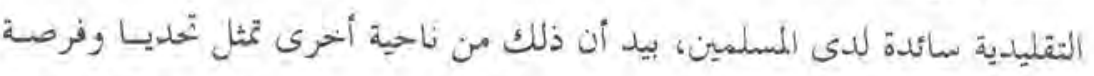

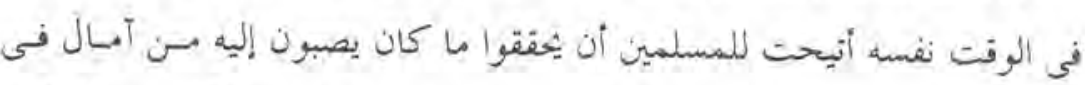
تطبيق تعاليمهم الدينية على نطاق أوسع للمجتمع. وبالاختصار كسانت الأفكار

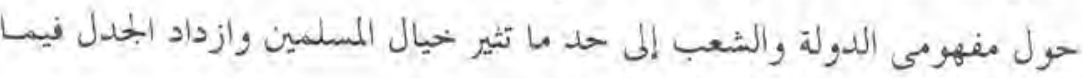
بينهم كثافة حول الصورة الأمثل القابلة للتطبيق العبلي. وهذا الكتاب الذى ألف معظمه علمساء انتربولوجيون، يعرض صسورة

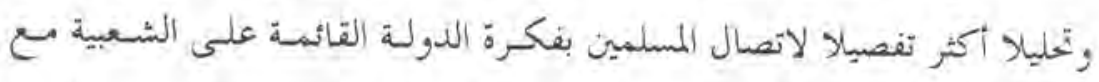
ثقربة المسـلمين بـالدول الثلاك في جنسوب شـرقى آسيا: اندونيسيا وماليزيا والفليبين. وهناك ثلاثة بحموعات في هـذا الكتـاب، أزفلـا تتعرض للعلاقـة بـين

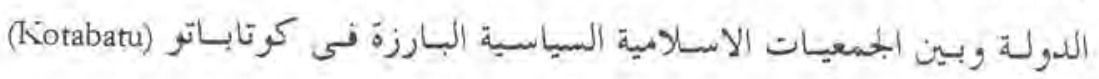

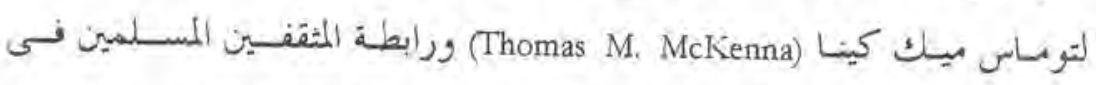
اندونيسيا لروبرت هيبنير (Robert W. Hefrner) ونهضـة العلدـاء لأندريـه فيفيـارد ؛ (Andree Feffiard) تقوم بها الحركات الاسلامية الاصلاحية في مستواها الجذرى باندونيسـيا لجـرن بويس (John R. Bowen) والحركية النجديديسة الاسـلامية بجـايو (Gayo) الفلبـين لباتريسيا هورفساتيش (Patricia Horvatich) وطائفة الأحمديـة بجزيـرة سـيمونول (Syamsul A.B.) وفى ماليزيا لشمس أب (Tawi-Tawi) ناوي - (Simunul)

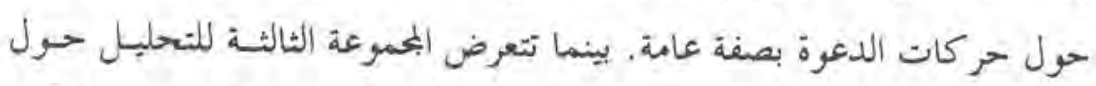
الكيفية التى استجاب بهـا المسلمون على المستوى الجـذرى بمختلف الأفكار

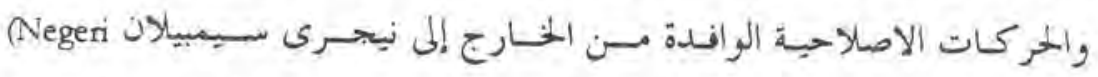
(Michael G. Peletz) وفي سلاوينسى الجنوبيـة Sembilan) بانذونيسيا لمارتين روتسلير (Martin Rossler). 
ولهذا الكتاب نلائة إسهامات هامة للدراسات الاسلامية يرتبط بعضهـا

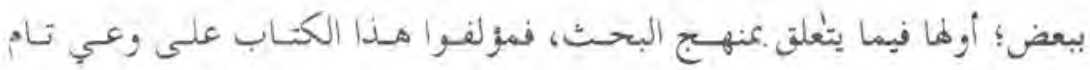

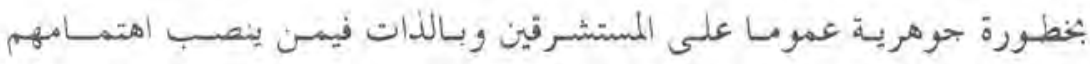

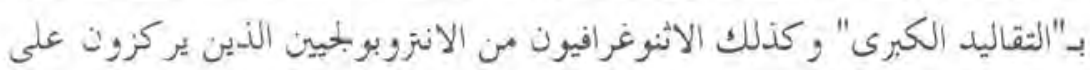

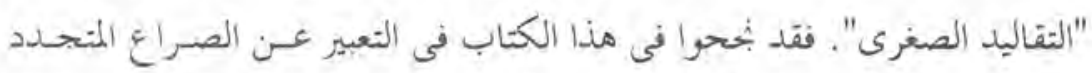

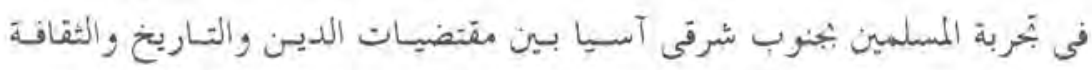

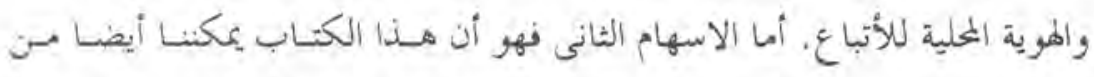

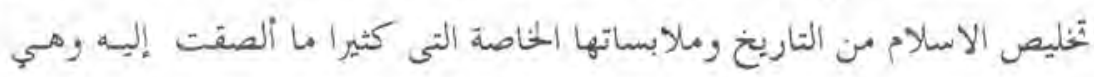

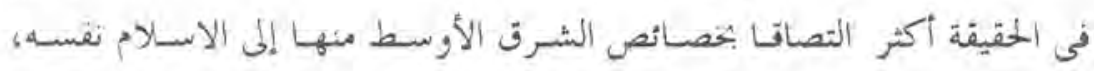

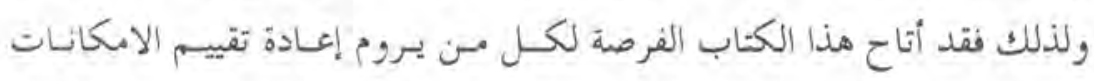

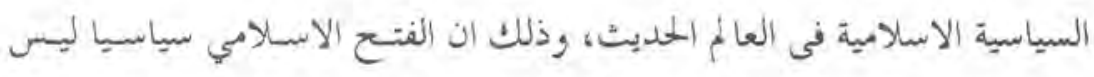

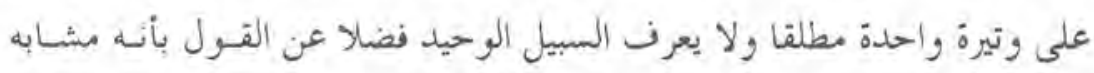

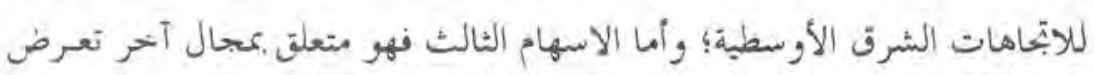

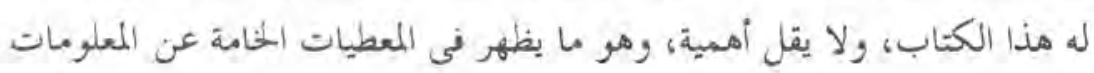

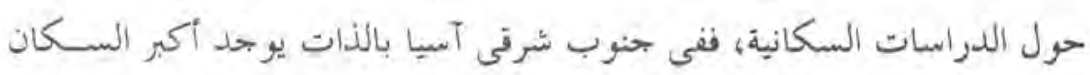

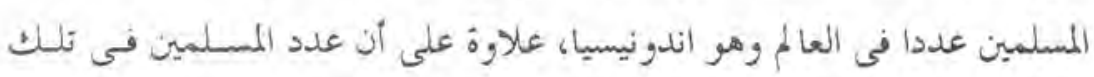

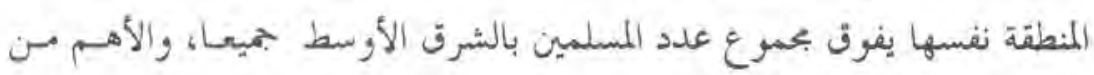

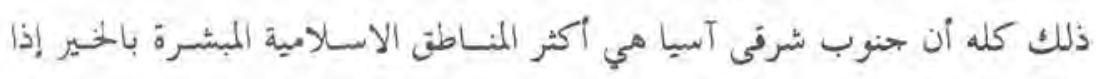

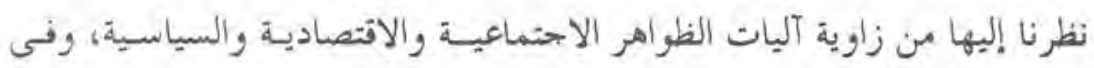

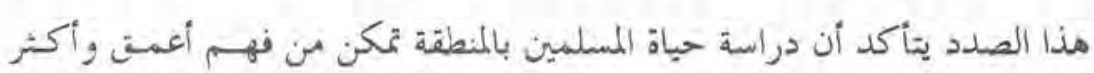
مفارنة حول الفروق المتعلقة باستجابة الاسلام للتحديث. 
Pada tahun 1985, pengamat Islam William Roff menulis satu analisis dan pengamatan penting mengenai bagaimana para sarjana Barat memperlakukan Islam di Asia Tenggara hingga saat itu. Menurutnya, "tampak ada keinginan amat menggebu (an extraordinary desire) di kalangan sebagian peneliti ilmu-ilmu sosial Barat untuk menyingkirkan (diminish), secara konseptual, tempat dan peran agama serta kebudayaan Islam ... dalam berbagai masyarakat Asia Tenggara." ${ }^{1}$

Pernyataan itu mungkin terasa terlalu hiperbolik (perhatikan katakata yang edisi Inggrisnya saya sertakan dalam tanda kurung di atas). Tetapi esensinya jelas mengandung kebenaran. Pertama, secara kuantitas jumlah karya-karya yang diterbitkan tidak seberapa, benar-benar tidak sebanding dengan begitu besarnya jumlah penduduk Muslim di wilayah ini. Sekadar diingat, di Asia Tenggaralah terletak negara dengan jumlah penduduk Muslim terbesar di dunia, yakni Indonesia. Selain itu, jumlah total kaum Muslim di wilayah itu sendiri lebih besar dibanding jumlah keseluruhan kaum Muslim di Timur Tengah, wilayah yang biasa dipandang sebagai asal Islam.

Dan kedua, dalam karya-karya yang ada memang terasa ada semacam kesengajaan atau kesepakatan diam-diam untuk "mengubur" Islam di bawah tradisi lokal yang dipandang lebih berperan. Pada dekade 1990-an, kritik seperti ini telah diperkuat oleh beberapa pengamatan lain seperti yang dikemukakan oleh Mark Woodward, John Bowen, Karel Steenbrink, Nurcholish Madjid, Azyumardi Azra, dan lainnya. ${ }^{2}$

Buku ini antara lain berguna untuk ikut mengatasi kekosongan dan kelemahan di atas. Dalam pengantarnya, Robert W. Hefner menyebutkan dua alasan mengapa pengabaian dan "penyingkiran" di atas, terhadap tempat dan peran Islam di berbagai masyarakat Asia Tenggara, tidak lagi dapat dibenarkan.

Pertama, pertumbuhan ekonomi di Malaysia dan Indonesia, dua negara dengan jumlah penduduk Muslim terbesar di Asia Tenggara, dewasa ini termasuk yang tertinggi di dunia. Dinamika ekonomi kedua negara itu telah menjadikan kedudukan keduanya cukup menonjol di dunia internasional. Kedudukan keduanya juga meningkat di mata para pemimpin Muslim di dunia, menjadikan kedua negara itu makin 
dihormati. Dinamika ekonomi itu juga telah menimbulkan spekulasi teoretis mengenai kemungkinan model lain, yang non-Barat, dari ekonomi pasar dan pluralisme budaya. (Pengantar ini tentu ditulis sebelum kedua negara itu terkena krisis ekonomi. Tetapi krisis ekonomi pun, yang masih berlangsung hingga kini, belum tentu merupakan akhir dari segalanya. Salah satu spekulasi yang muncul malah menyebutkan, dinamika ekonomi yang ada sebelumnya itu justru akan makin terkelola dengan baik setelah landasan pertumbuhan ekonomi itu sendiri diatasi. Jadi, dalam perspekrif ini, krisis ekonomi itu sendiri adalah semacam hikmah terselubung.)

Kedua, yang lebih penting dari butir pertama di atas, Islam di Asia Tenggara tidak lagi dapat diabaikan karena, sejak akhir dekade 1970 an, wilayah ini telah mengalami kebangkitan agama yang tidak pernah ada presedennya: masjid-masjid berdiri di kota-kota dan desadesa; sekolah-sekolah agama dan acara-acara peribadatan bermunculan dengan maraknya; buku-buku, majalah-majalah, dan koran-koran Islam makin banyak yang terbit dengan pasar yang makin membesar; dan, yang penting sekali, kelas menengah Muslim yang amat terdidik mulai angkat bicara mengenai soal-soal yang menjadi ciri khas kepedulian manusia modern, termasuk soal tempat, peran dan kedudukan kaum perempuan dalam masyarakat, tantangan pluralisme, tentang kompatibilitas Islam dengan ekonomi pasar, dan tentang hubungan yang pas antara agama dan negara.

Ada banyak faktor yang turut mempengaruhi kebangkitan agama di wilayah ini. Di fora internasional, dekade 1970-an sendiri dianggap sebagai dekade kebangkitan Islam, bersamaan dengan masuknya kaum Muslim ke abad XV hijrah. Ada banyak gejala yang menyiratkan kebangkitan Islam saat itu: karena uang minyak, kekuatan ekonomi negara-negara Timur Tengah meningkat pesat; pada tahun 1978, di Iran berlangsung revolusi Islam yang dipimpin para mullah; penolakan terhadap nasionalisme sekular terjadi hampir di seluruh negara dengan penduduk mayoritas Muslim; dan lain sebagainya.

Meskipun menyadari kemungkinan pengaruh internasional ini, buku ini sengaja lebih memfokuskan perhatian pada dinamika internal kaum Muslim di Asia Tenggara sendiri, dan lebih khusus lagi pada konteks lokal perjumpaan kaum Muslim dengan institusi negara-bangsa (nation-state) yang sepenuhnya baru, yakni bentukan abad XX. Dengan "jangkauan infrasttuktural" (infrastructural reach)-nya yang jauh melampaui jangkauan sejenis yang dimiliki negara-negara tradisional sebelumnya, negara-negara nasional ini sangat besar pe- 
ngaruhnya dalam pengaturan masalah-masalah publik dan sangat dalam intervensinya bahkan terhadap domain-domain paling intimate dalam kehidupan privat kaum Muslim.

Dalam hal ini, negara-bangsa tampil sebagai lembaga baru yang tampak sebagai makhluk bermuka-janus bagi kaum Muslim. Pada satu sisi, lembaga ini merupakan ancaman terhadap model organisasi dan otoritas tradisional masyarakat Muslim. Identitas tradisional seorang Muslim sebagai bagian dari Ummah Islam yang universal, misalnya, "diganggu" oleh kenyataan bahwa ia kini juga adalah seorang warganegara sebuah negara nasional. Tetapi, di sisi lain, kemunculan negara-bangsa juga dipandang sebagai tantangan dan kesempatan baru bagi kaum Muslim untuk merealisasikan impian abadi mereka, yaitu melakukan transformasi sosial-keagamaan pada tingkat masyarakat yang lebih luas. Pendek kata, lembaga negara-bangsa, yang-sekali lagi-sepenuhnya baru itu, pada titik-titik tertentu telah menggugah imaginasi kaum Muslim, dan juga mengintensifkan perdebatan di kalangan mereka, mengenai bentuk masyarakat Muslim yang ideal dan pada saat yang sama viable di tingkat praktis.

Hubungan khusus antara kebangkitan Islam di atas dan keberadaan lembaga negara-bangsa berkali-kali ditekankan dalam buku ini-bukan saja oleh Hefner dalam pengantarnya, melainkan juga oleh hampir semua kontributor dalam buku ini. Oleh Hefner, hubungan itu dilihat dalam konteks fasilitas apa saja yang disediakan negara-bangsa, yang pada kenyaraannya, entah disengaja entah tidak, bermanfaat bagi berlangsungnya kebangkitan agama. Tiga yang terpenting di antaranya adalah: (1) tersedianya pendidikan yang bersifat massif yang jelas menguntungkan kaum Muslim sebagai mayoritas penduduk; (2) pertumbuhan kelas menengah yang dengan sendirinya sebagian besarnya Muslim; dan (3) berkembangnya wacana Islam baru-wacana yang berorientasi lebih kepada kebutuhan publik pada umumnya dan bukan hanya kalangan agamawan dalam pengertiannya yang terbatas.

Namun, berbeda dari pada umumnya pengamatan para sarjana Barat mengenai kebangkitan Islam, buku ini menekankan bahwa yang disuarakan bukanlah satu hal yang sama dan tunggal. Malah, salah satu ciri khas kebangkitan Islam di Asia T'enggara yang paling menonjol adalah keragaman suara yang dinyatakan dan vitalitas perdebatan yang muncul karenanya. Diakui bahwa di wilayah ini juga dapat ditemukan suara-suara "Islam militan", jenis Islam yang biasa distereotipekan para sarjana Barat sebagai "Islam fundamentalis". 
Tetapi wacana yang dominan bukanlah suara Islam yang demikian itu, melainkan suara Islam yang dicirikan oleh kombinasi antara pluralisme, dinamisme intelektual, dan keterbukaan untuk berdialog dengan berbagai aktor dan lembaga non-Muslim.

Berisi tulisan-tulisan yang sebagian besarnya dikerjakan para antropolog, buku ini menyajikan gambaran dan analisis cukup mendetail mengenai perjumpaan kaum Muslim dan negara-bangsa di atas, dengan kasus pengalaman kaum Muslim di tiga negara Asia Tenggara: Indonesia, Malaysia, dan Filipina. Semua tulisan dikelompokkan ke dalam tiga bagian besar.

Kelompok yang pertama berbicara mengenai hubungan antara negara dan organisasi-organisasi sosial dan politik di Indonesia dan Filipina. Bagian ini dibuka dengan tulisan Thomas M. McKenna mengenai pengalaman dan identitas kaum Muslim di Kotabato, satusatunya wilayah dengan penduduk mayoritas Muslim di Filipina Selatan.

Dengan maksud menawarkan cara baca baru mengenai identitas kaum Muslim di Filipina, McKenna pertama-tama membongkar asumsi lama mengenai koherensi kemusliman mereka seperti yang dikemukakan banyak sarjana sebelum ini. Menurutnya, tidak ada landasan kokoh dalam catatan sejarah yang membenarkan klaim bahwa peperangan orang-orang Moro (Moro Wars) melawan penjajah Spanyol telah memperteguh dan memperkokoh rasa identitas bersama seluruh kaum Muslim di Filipina, yang "memotong" batas-batas bahasa dan geografis yang sebelumnya dan hingga kini masih memisahkan mereka.

Perpindahan kolonialisme dari Spanyol ke Amerika juga tidak memperkokoh rasa identitas bersama itu. Lewat kebijakan kolonial yang antara lain diarsiteki oleh Najeeb M. Saleeby, sarjana Kristen keturunan Syria yang rupanya tahu banyak mengenai hal-ihwal kaum Muslim, kaum Muslim di Filipina di-devide et impera baik langsung maupun tidak langsung. Dari situlah muncul ketegangan dan perpecahan di antara para elite kaum Muslim: antara para tetua adat, ulama didikan Timur Tengah, dan intelektual Muslim baru lulusan berbagai universitas sekular di dalam negeri.

Ketika McKenna mengakhiri risetnya di Filipina pada September 1986, ketegangan dan perpecahan itu masih terasa. Hal itu terutama 
dicerminkan mundurnya Hashim Salamat dari kedudukannya sebagai Wakil Ketua Komite Pusat Front Pembebasan Nasional Moro (Moro National Liberation Front), pada tahun 1979. Salamat adalah lulusan al-Azhar, Mesir, dan merasa kecewa terhadap kepemimpinan Nur Misuari, sarjana ilmu politik lulusan Universitas Filipina, karena yang terakhir itu menyepakati ajakan damai pemerintah pada tahun 1977. Enam tahun kemudian, Salamat membentuk Front Pembebasan Islam Moro (Moro Islamic Liberation Front), untuk "menegaskan Islam sebagai landasan pokok perjuangan bangsa Moro."

Dengan mengungkit semua data sejarah itu, dan pemaparan etnografisnya mengenai kepercayaan sehari-hari rakyat biasa di Kotabato yang pada umumnya diwarnai takhayul dan khurafat seperti yang dikecam para ulama reformis dari Timur Tengah, yang hendak digarisbawahi McKenna adalah kenyataan bahwa di Filipina tidak pernah ada wacana keislaman yang dominan dan all-encompassing. Kemusliman mereka tidak pernah begitu saja bersifat oposisional terhadap identitas etnis seperti yang dikonstruksikan untuk mereka oleh para pemimpin politik. Kemusliman mereka adalah produk dari dialog antara beberapa tatanan budaya yang punya potensi berbenturan: berbagai imperatif universal Islam (seperti yang dipahami pada tingkat lokal) dan nilai-nilai yang sudah lama tertubuhkan dalam masyarakat. Karenanya, identitas keislaman mayoritas kaum Muslim di Kotabato tidak pernah tetap. Hal itu akan selalu dibentuk dan dibentuk kembali oleh dialog pada tiga tingkatan yang sama-sama kompleks dan saling terkait: antara kaum Muslim biasa dengan para ulama independen mengenai corak keberagamaan; antara para pemimpin tradisional dan para pengikut mereka mengenai sumber legitimasi politik; dan antara kaum Muslim pada umumnya dengan orang-orang Kristen yang mendominasi Filipina mengenai berbagai parameter pengaturan wilayah otonom.

Pada tulisan kedua, "Islamization and Democratization in Indonesia," Robert W. Hefner menganalisis berbagai persoalan di sekitar hubungan antara beberapa perspektif tentang islamisasi yang berkembang di Indonesia kontemporer dengan masa depan demokrasi dan demokratisasi. Kasus yang ditiliknya secara cukup mendetail adalah konteks sosial, ekonomi, politik, dan budaya di sekitar pembentukan,Ikatan Cendekiawan Muslim se-Indonesia (ICMI) dan tahun-tahun pertama berjalannya organisasi itu. Sebagian besar kandungan tulisan ini pernah diterbitkan di tempat lain, dan cukup banyak dibicarakan di Indonesia sehingga tidak perlu lagi disinggung di 
sini. Tetapi sedikit perubahan-lebih tepatnya disebut penambahanyang ada dalam tulisan ini memperlihatkan penilaian baru dan terakhir penulisnya yang layak diperhatikan.

Berbeda dari hampir semua ahli tentang Indonesia yang pernah menyinggung atau berbicara khusus soal ICMI dalam tulisan mereka, yang terutama melihat pembentukan ICMI dalam konteks power struggle di tingkat elite, ${ }^{3}$ Hefner terutama melacak pembentukan organisasi itu dari dinamika internal kaum Muslim sendiri. Dengan mendasarkan diri terutama pada pengamatan Nurcholish Madjid tentang mobilitas vertikal kaum santri yang sangat pesat pada dekade 1960-an dan 1970-an, Hefner memandang kelahiran ICMI sebagai kristalisasi mobilitas vertikal itu dalam bentuk organisasi kuasi-politik yang berpengaruh. Dilihat dari perspektif ini, pembentukan ICMI adalah simbol berdamainya Islam dengan negara (Orde Baru), yang menandai berakhirnya sikap saling memusuhi dan saling curiga satu sama lain.

Bukan itu saja: Hefner juga menyambut baik perkembangan ini sebagai indikasi akan makin membaiknya kualitas kehidupan ekonomi, sosial dan politik di Indonesia. Demikian, karena setidaknya sebagian aspirasi dan kepentingan kaum Muslim, umat yang jumlahnya terbesar di negeri ini, sudah terakomodasi. Selain itu, di ICMI sendiri terlibat para aktivis Muslim yang sebelumnya dikenal sebagai tokoh yang keras menyuarakan keharusan demokratisasi dan penghormatan hak-hak asasi manusia di Indonesia.

Tetapi Hefner, yang menyelesaikan tulisan ini pada bulan Agustus 1996, dengan jujur mengakui berbagai perkembangan tidak menggembirakan dalam "proyek" demokratisasi ICMI yang semula diyakininya. Perkembangan itu misalnya adalah: diamnya para tokoh ICMI dalam kasus pembredelan Tempo, Detik, dan Editor; diamnya ICMI ketika Sri Bintang Pamungkas, yang nota bene adalah salah seorang pengurus terasnya, di-recall dari keanggotaannya di DPR; dan kritik banyak tokoh ICMI terhadap pernyataan orang seperti Nurcholish Madjid tentang perlunya oposisi dan demokratisasi kehidupan politik, karena dianggap naif dan tidak peka terhadap realpolitik.

Hefner mengakhiri tulisan ini tanpa kesimpulan definitif mengenai dilema islamisasi dan demokratisasi dalam kasus ICMI. Ia hanya menyatakan bahwa berbagai perkembangan sejak tahun 1994 makin mempersulit pemecahan dilema itu: bagaimana menyeimbangkan kepentingan umat dengan kepentingan bangsa. Dan ketika ia menyatakan, di penghujung tulisannya, bahwa "ketegangan ini telah diman- 
faatkan oleh para penyusun strategi Orde Baru dalam upaya mereka untuk membenturkan kaum Muslim dengan para aktivis prodemokrasi yang sekular," rasanya ia sudah cukup merevisi tesisnya yang awal, yang tampak optimistik mengenai peran demokratisasi ICMI.

Tulisan ketiga masih tentang Islam di Indonesia. Kali ini Andrée Feillard memaparkan sejarah hubungan Nahdlatul Ulama (NU, yang disebutnya "Islam tradisionalis") dengan negara. Pada bagian akhir tulisannya, Feillard juga menganalisis upaya organisasi itu untuk memperoleh legitimasi dan menjangkau pembaruan belakangan ini. Tidak ada yang terlalu baru dalam tulisan ini, terutama bagi kita di Indonesia. Tetapi tulisan ini tetap sangat penting, mengingat masih amat jarangnya informasi mengenai NU, sebuah organisasi dengan jumlah pengikut sangat besar, dalam bahasa Inggris. ${ }^{+}$

Feillard menyebutkan bahwa hubungan NU dan negara berjalan dengan baik sebelum masa Orde Baru. Para ulama NU mendukung Sukarno pada tahun 1940, 1945 dan 1959, sekalipun ada perbedaan sangat jelas di antara kedua belah pihak dalam persoalan hubungan antara agama dan negara. Perbedaan pandangan ini "diredam" oleh tradisi akomodasionis Islam Sunni yang menjadi basis doktrinal NU.

Memasuki masa Orde Baru, hubungan itu menjadi sangat tergang. gu. Hal itu sebagian disebabkan hubungan baik NU dengan Sukarno, yang menjadi musuh Orde Baru. Rusaknya hubungan itu amat merugikan NU pada sebagian besar babakan sejarah Orde Baru. Sumberdaya ekonomi dan politik banyak yang hilang, banyak akrivitas dakwah dan lainnya terganggu, dan banyak kader organisasi yang menarik diri.

Di bawah kepeloporan Abdurrahman Wahid, NU lalu melakukan apa yang kemudian dikenal sebagai langkah kembali ke Khittah 1926. Dengan langkah itu, maka NU menarik diri dari keanggotaannya di Partai Persatuan Pembangunan (PPP). NU juga menjadi pelopor organisasi sosial yang menerima asas tunggal Pancasila. Dengan penerimaan itu, maka NU berarti berani menarik garis tegas antara ideologi dan agama, dan dengan begitu secara terbuka menyatakan dukungannya terhadap cita-cita nasional.

Menurut Feillard, langkah di atas bukan terutama didasarkan kepada oportunisme dalam arena politik nasional, melainkan sebuah strategi yang penting untuk mempertahankan diri (not so much oppor. tunism in the national political arena as an urgent strategy for survival). Meminjam kata-kata Mitsuo Nakamura, langkah itu berarti "pembe- 
basan Islam dari stigma dan hambatan-hambatan politik."

Bagian kedua buku ini ("Reformers and Reformisms") berbicara tentang operasi berbagai gerakan reformasi Islam pada tingkat lokal di Indonesia, Filipina dan Malaysia, Kasus dari Indonesia ditulis antropolog John Bowen, tentang modernisme Islam di Gayo. Yang dikisahkan Bowen adalah perdebatan mengenai pentingnya mengucapkan niat dalam awal salat (ushalli) antara kelompok pembaru (yang disebut kaum muda) dengan kelompok ulama tradisionalis (yang disebut "kaum tua").

Tetapi yang digarisbawahi Bowen bukan debat itu sendiri, melainkan makna penting berbagai strategi, keyakinan dan retorika yang digunakan dalam fenomena keagamaan, karena semuanya itu mencerminkan corak-corak aspirasi dan kepentingan kelompok-kelompok masyarakat yang terlibat. Dalam tulisan itu, yang sulit untuk diparafrasekan di sini, kita dapat menelusuri jalinan-jalinan ekonomi dan sosial yang menempatkan kepentingan kaum muda, yang berorientasi Islam Wahabi, dalam posisi yang berhadapan dengan kepentingan old establishment, kaum tua. Dalam seluruh proses ini, debat mengenai niat sebelum salat itu tidak lebih dari medium perseteruan kepentingan elite.

Sementara itu, dalam artikel kedua, Patricia Horvatich menulis mengenai masuknya gerakan Ahmadiyah di Pulau Simunul, TawiTawi, Filipina. Yang membawa masuk ajaran Ahmadiyah ke sana adalah $\mathrm{H}_{3 j \mathrm{i}}$ Hussein, pada tahun 1957, Seperti diketahui, A hmadiyah pertama kali muncul di India pada akhir abad XIX, dan ajaran-ajarannya ditolak oleh sebagian besar ortodoksi Islam Sunni, terutama cabang Qadiyaninya, yang mengklaim bahwa Mirza Ghulam Ahmadpendiri ajaran ini-adalah seorang nabi.

Yang cukup menarik adalah, ajaran-ajaran Ahmadiyah itu cukup mendapat sambutan positif di Simunul. Sedikitnya Horvatich menyebutkan empat alasan untuk penerimaan itu. Pertama, ajaran-ajaran Ahmadiyah itu disampaikan oleh orang-orang yang prestisius, berpengaruh dan karismatis. Kedua, orang-orang juga tertarik kepadanya karena prestise yang diberikan gerakan itu kepada mereka, karena dengan begitu mereka masuk sebagai anggota sebuah gerakan internasional yang dikelola sebuah elite terdidik yang dekat dengan pusat Islam. Dalam hal ini, gerakan Ahmadiyah diidentikkan dengan gerakan kaum intelektual. Ketiga, orang-orang berpandangan bahwa ajaran-ajaran Ahmadiyah sejalan dengan pemahaman dan cita-cita mereka, Mereka yang tertarik dengan ajaran-ajaran Ahmadiyah ini 
biasanya adalah orang-orang yang sudah berkenalan dengan reformasi Islam, dan mereka memandang Ahmadiyah dapat diterima. Alasan keempat adalah karena ajaran-ajaran Ahmadiyah itu memang menemukan mediumnya yang pas, sehingga ajaran-ajaran itu memperoleh "akar"-nya. Dalam hal ini, oleh kaum terdidik di Simunul, "kebenaran" dipandang tidak lagi merupakan milik khusus para ulama, melainkan dapat ditemukan di dalam teks yang bisa diakses siapa saja.

Dalam kasus ini, apa yang sudah dikemukakan di atas, mengenai pengaruh pendidikan yang massif terhadap reformasi Islam, menemukan bukti paling jelas. Ketika masih dijajah Amerika, persisnya tahun 1906, semua orang diharuskan ikut pendidikan dasar. Maksudnya adalah agar nantinya semua rakyat Filipina, kaum Muslim sekalipun, dapat berkembang menjadi warganegara yang baik.

Kebijakan seperti ini kemudian dilanjutkan pemerintahan Filipina pascakolonial. Pada tahun 1957, mereka membentuk Komisi Integrasi Nasional (Commission on National Integration) untuk membantu perkembangan kelompok-kelompok minoritas. Tujuan akhirnya adalah integrasi nasional yang kokoh. Dalam hal ini, aspek pendidikan paling diutamakan. Kepada kaum Muslim malah disarankan agar mereka mulai menyekolahkan anak-anak mereka sedini usia lima tahun.

Kebijakan di atas didasarkan kepada asumsi bahwà pendidikan model Barat akan dengan sendirinya mereduksi signifikansi Islam dalam masyarakat. Asumsi ini salah total, karena pendidikan massif terbukti malah mendukung aktivisme Islam.

Dalam kasus yang diteliti Horvatich, kalangan terdidik Muslim di Simunul bukan saja dapat memahami literatur dalam bahasa Inggris (yang menjadi sumber utama penelusuran dan penyampaian ajaranajaran Ahmadiyah), melainkan juga dapat mengembangkan metode belajar dan berpikir yang memungkinkan mereka mengakses pengetahuan yang abstrak dan tak terbatas. Dengan kemampuan iculah mereka mengapresiasi ajaran-ajaran Muhammadiyah, dan pada saat yang sama mempertanyakan dan menolak klaim-klaim "kebenaran" kalangan ulama.

Artikel terakhir pada bagian ini ditulis Shamsul A.B., seorang sosiolog Malaysia, tentang pada umumnya gerakan dakwah di Malaysia. Yang dimaksud dengan gerakan dakwah adalah gerakan-gerakan Islam yang muncul setelah terjadinya konflik antaretnis di Malaysia pada tahun 1969, yang amat membekas dalam benak seluruh 
masyarakat Malaysia dan terus mempengaruhi kehidupan sosial, ekonomi dan politik negeri itu di kemudian hari.

Hingga saat ini, gerakan dakwah itu dapat diterangkan menurut tiga fase. Pada fase pertama (1969-1974), gerakan itu bersifat inward looking dengan kepedulian utama reedukasi kaum Muslim. Sikap politiknya moderat dan tergabung dalam gerakan politik mahasiswa Malaysia pada umumnya, dengan tuntutan utama keadilan sosial dan ekonomi bagi rakyat lemah dalam sebuah masyarakat yang plural. Tetapi missi gerakan ini tetap kental warna Islamnya, dengan tujuan membangun masyarakat Islami dan Islam menjadi ideologi politiknya. Basis gerakan ini adalah mahasiswa pada fakultas-fakultas ilmuilmu sosial dan humaniora.

Fase kedua berlangsung antara tahun 1975 hingga 1979. Model gerakan dakwah yang dominan pada fase ini adalah gerakan radikal, yang dibawa masuk ke dalam negeri oleh para sarjana bidang sains yang belajar di luar negeri atas sponsor pemerintah. Basis gerakan ini adalah beberapa perguruan tinggi bidang sains dan teknik yang sengaja didirikan pemerintah untuk menampung para lulusan di atas. Berkat militansi para aktivisnya, gerakan ini juga sangat berpengaruh di kalangan para siswa sekolah menengah atas.

Sementara itu, fase ketiga berlangsung antara tahun 1979 hingga 1990. Fase ini dicirikan upaya pemerintah mengakomodasi gerakangerakan dakwah di atas dengan menerapkan program-program yang berorientasi Islam, membeayai organisasi-organisasi Islam lokal dan internasional, membangun lembaga-lembaga ekonomi Islam, menyuarakan kebijakan luar negeri yang pro-Muslim, dan terlibat aktif dalam perpolitikan blok Islam. Gerakan ini menekankan keharusan sebuah pendekatan yang moderat terhadap Islam dalam sebuah masyarakat multietnis seperti Malaysia.

Langkah-langkah pemerintah ini berhasil meyakinkan para aktivis gerakan dakwah yang pertama, yang berorientasi Islam moderat, untuk mendukung pemerintah dan terlibat dalam pemerintahan. Figur yang menonjol dalam konteks ini adalah Anwar Ibrahim, dengan Angkatan Belia Islam Malaysia (ABMM) berfungsi sebagai mesin gerakan. Akan halnya gerakan dakwah yang radikal, mereka tetap dominan di banyak kampus dan tidak sepenuhnya dapat dikontrol oleh pemerintah.

Kontes antara kedua model gerakan dakwah itu akan terus mewarnai hubungan antara Islam dan negara di Malaysia. Sementara gerakan yang pertama menekankan perlunya Islam menawarkan lan- 
dasan moral dan spiritual bagi masa depan industrialisasi Malaysia, gerakan yang kedua terus mendesakkan Islamisasi negara secara lebih tegas.

Pada bagian ketiga buku ini, disajikan pemaparan dan analisis mengenai respons kaum Muslim di tingkat akar-rumput, masyarakat biasa, terhadap berbagai wacana dan gerakan reformasi yang didesakkan dari luar. Kasusnya diambil dari Negeri Sembilan di Malaysia, ditulis oleh Michael G. Peletz, dan dari Sulawesi Selatan, Indonesia, ditulis oleh Martin Rössler.

Dalam kedua kasus ini, tampak sikap ambivalen pada umumnya kaum Muslim biasa terhadap gerakan-gerakan reformasi dan pembaruan yang pertama kali muncul di kota dan digerakkan kaum Muslim kelas menengah perkotaan. Resistensi terhadap gerakan-gerakan itu pada umumnya muncul karena masyarakat biasa memandang apa yang dibawa oleh para aktivis gerakan itu mengancam nilai-nilai lama. Mereka lebih memilih untuk mempertahankan nilai-nilai lama itu - bukan karena nilai-nilai lama itu sudah diwariskan atau yang semacam itu, melainkan karena memang mereka memandangnya memiliki makna intrinsik tersendiri. Makna intrinsik inilah yang seringkali tidak sepenuhnya dapat dipahami oleh logika "kebenaran" para aktivis gerakan reformasi dan pembaruan. Dalam hal ini, mereka memandang bahwa apa yang ada pada mereka, pandangan-dunia mereka, sudah mencukupi.

Secara keseluruhan, buku ini, dengan banyak tulisan dan berisi beragam tema, sedikitnya memberikan tiga sumbangan penting yang saling terkait. Pertama, menyangkut metodologi, para penulis dalam buku ini sangat menyadari bahaya esensialisme pada umumnya para orientalis (yang terutama menekankan "tradisi besar") dan etnografisme pada umumnya para antropolog (yang terutama menekankan "tradisi kecil"). Dari tulisan-tulisan mereka, kita dapat menangkap ketegangan kreatif, dalam pengalaman keberagamaan kaum Muslim di Asia Tenggara, antara imperatif-imperatif transenden Islam dengan sejarah, budaya dan identitas lokal para pemeluknya. Kedua, buku ini juga memungkinkan kita melepaskan politik Islam dari sejarah dan situasi yang khusus yang sering dilekatkan kepadanya, yakni sejarah dan situasi yang sebenarnya lebih banyak berhubungan dengan kekhasan Timur Tengah daripada Islam itu sendiri. Dengan menya- 
jikan berbagai kasus hubungan politik antara Islam dan negara di Asia Tenggara, buku ini menawarkan kesempatan bagi siapa pun untuk mengevaluasi kembali keragaman potensi dan ekspresi politik Islam di dunia modern. Bahwa potensi dan ekspresi politik Islam sama sekali tidak tunggal dan monolitik, apalagi identik dengan yang berkembang di Timur Tengah.

Ketiga, wilayah yang dibahas dalam buku ini bukan sebarang wilayah Islam, melainkan wilayah Islam yang sangat penting belakangan ini. Hal ini pertama-tama tampak pada data-data "kasar" demografisnya, dan dinamika ekonominya, seperti sudah disinggung di awal tulisan ini. Dari sudut ini, maka studi mengenai kaum Muslim di wilayah ini bukan saja tidak layak untuk diabaikan, seperti yang dikecam William Roff, melainkan bahkan barangkali tidak salah untuk mulai diprioritaskan. 


\section{Catatan Akhir}

1. Lihat William R. Roff, "Islam Obscured: Some Reflections on Studies of Islam \& Socjery in Southeast Asia," Archipel 29 (1985), hlm. 7.

2. Lihat misalnya "Pendahuluan" panjang Mark R. Woodward untuk buku yang disuntingnya, Towurd a New Paradigm: Recent Developments in Indonesian Is. lamic Thought (Tempe, Arizona: Arizona State University Program for Southeast Asian Studies, 1996); John R. Bowen, "Western Studies of Southeast Asian Islam: Problem of Theory and Practice," dalam Studia Islamika, Vol. 2, No. 4, hlm. 69-85; Azyumardi Azra, "Orientalisme dan Studi Islam Asia Tenggara," Islamika, No. 3, Januari-Maret 1994, hlm. 108-115; dan Nurcholish Madjid, "Islam di Mata Orientalis," dalam kumpulan karangannya, Islam Agama Peradah. an: Membangun Makna dan Relevansi Doktrin Islam dalam Sejarah (Jakarta: Paramadina, 1995), hlm. 297-318; dan Karel Steenbrink, Dutch Colonialism and Indo. nesian Islam: Contucts and Conflicts 1596-1950, translated from the Dutch by Jan Steenbrink and Henry Jansen (Amsterdam: Rodopy, 1993).

3. Lihat misalnya tulisan-tulisan R, William Liddle, "ICMI dan Masa Depan Politik Islam di Indonesia," dalam Nasrullah Ali-Fauzi (ed.), ICMI antara Status Quo dan Demokratisasi (Bandung: Mizan, 1995), hlm. $201-223$ dan "Giliran Islam di dalam Politik Indonesia: Sebuah Penjelasan Berpusat-Negara," dalam R. William Liddle, Islam, Politik dan Modernisasi (Jakarta: Pustaka Sinar Harapan, 1997), hlm. 65-99.

4. Hal ini diakui sendiri oleh Abdurrahman Wahid dalam "Kata Pengantar"-nya untuk buku yang disunting Greg Barton dan Greg Fealy (eds.), Nahdlatul Ulama, Traditional Islam and Modernity in Indonesia (Clayton: Monash Asia Institute, 1996).

Ihsan Ali-Fauzi adalah peneliti pada Lembaga Studi dan Pengembangan Etika Usaba Indonesia (LSPEUI), Jakarta. 